\title{
Impact of Taedia scrupeus (Hemiptera: Miridae) Feeding on Cluster Development in Concord Grapes
}

\author{
TIMOTHY MARTINSON, ${ }^{1}$ DANIELLE BERNARD, GREG ENGLISH-LOEB, AND TED TAFT, JR.
}

Department of Entomology, NYS Agricultural Experiment Station, Cornell University, Geneva NY 14456

\begin{abstract}
J. Econ. Entomol. 91(2): 507-511 (1998)
ABSTRACT Taedia scrupeus (Say) feeds on grape clusters and shoots early in the growing season. The impact of nymphal and adult feeding was assessed at the individual shoot level by confining nymphs within sleeve cages at 4 different times: prebloom, bloom, postbloom, and prebloom to postbloom. Prebloom feeding significantly reduced the number of berries per cluster and average berry weight, resulting in a $68 \%$ reduction in cluster weight. When nymphs were allowed to feed from prebloom to postbloom, cluster weight was reduced by $71 \%$. Feeding only during bloom and postbloom did not affect cluster weight. Prebloom feeding reduced the number of florets per cluster, berries per cluster, and berry weight. The whole-vine impact of $T$. scrupeus was examined in a commercial Concord vineyard, where 3-vine experimental units were treated with carbaryl to remove $T$. scrupets or were left untreated. Unsprayed vines, with a mean density of $20 T$. scrupeus per vine, yielded $10.4 \mathrm{~kg}$ per vine, and sprayed vines without injury yielded $14.1 \mathrm{~kg}$ per vine. The yield component most strongly affected was the number of clusters per vine, which averaged 165.4 and 131.8 per vine in sprayed and unsprayed vines, respectively. Each T. scrupeus nymph was associated with $0.18 \mathrm{~kg}$ of crop loss, suggesting that as few as 0.5 nymphs per vine can cause economic injury. Where treatment of vineyards to prevent $T$. scrupeus injury is warranted, it must be applied during the prebloom period.
\end{abstract}

KEY WORDS Taedia scrupeus, grapes, Vitis, economic injury level

Taedia scrupeus (SAY) was first reported to be a pest of grapes in the Lake Erie region of New York and Pennsylvania early in this century (Felt 1915). Nymphs emerge shortly after budbreak and feed on young shoots and developing clusters, impairing cluster and shoot development (Jubb 1979). Felt (1915) described the injury as resulting in ragged clusters and presented data showing $40 \%$ of the berries on an individual vine destroyed. Jubb (1979) reported sporadic infestations of $T$. scrupeus requiring treatment. However, little else has been published regarding feeding habits or injury associated with this pest.

Following reports of significant infestations in several vineyards in 1993 and 1994, we initiated studies on 'Concord' grapes better to characterize the phenology of this pest and the impact of injury on cluster development and productivity. In this article, we report observational data on T. scrupeus phenology, results of small-scale studies testing the impact of caged nymphs on development of individual clusters, and finally overall impact of native population levels on yield components of Concord grapes.

\section{Materials and Methods}

Phenology and Feeding Behavior. Nine vineyards in the Lake Erie region were monitored weekly from 8

\footnotetext{
${ }^{\prime}$ Current address: Finger Lakes Grape Program, Cornell Cooperative Extension-Yates County, 110 Court Street, Penn Yan, NY 14527.
}

May to 3 August, 1995. Date of emergence of nymphs and adults was recorded, and observations of feeding locations were made for both nymphs and adults in field and laboratory settings. Approximately 100 adults were collected on 14 June and placed in a $1.5-\mathrm{m}^{3}$ cage surrounding a mature Vitis Labruscana Bailey Concord vine. The vine then was dissected to determine location of eggs.

1995 Cage Study. Cohorts of nymphs were caged at 4 different time intervals on individual shoots in a Concord vineyard at the Vineyard Laboratory in Fredonia, NY. For each treatment, mesh sleeve cages ( 1 $\mathrm{m}$ long by $30 \mathrm{~cm}$ diameter) were placed on 2 randomly chosen shoots on each of 25 vines. Three to 5 fieldcollected T. scrupeus nymphs were introduced to 1 of the sleeve cages. Nymphs were excluded from the other caged shoot. Nymphs were caged for a 1-wk period at prebloom (31 May-7 June), bloom (14-21 June), or postbloom (28 June-5 July) or a 6-wk period from prebloom to postbloom (31 May-5 July) after which they were recovered from field cages and counted in the laboratory.

After treatment, all T. scrupeus were removed from cages, transferred to shell vials, and the number and growth stage of live and dead individuals were determined. The number of florets in the basal cluster of each caged shoot, except the prebloom-postbloom treatment, was counted on 7-8 June. This count was made after the initial prebloom treatment was com- 
Table 1. Number of T. scrupeus recovered from experimental units (sleeve cages) after 1-6 wk on Concord vines at Fredonia, NY, in 1995

\begin{tabular}{|c|c|c|c|c|c|c|c|c|}
\hline \multirow{2}{*}{ Treatment } & \multirow{2}{*}{$n$} & \multirow{2}{*}{ Dates caged } & \multicolumn{2}{|c|}{ T. scrupets recovered (mean $\pm S E M$ ) } & \multicolumn{4}{|c|}{ Stage distribution when recovered } \\
\hline & & & Alive & Dead & Instar 1-3 & Instar 4-5 & Adult & $n$ \\
\hline Prebloom" & 24 & 31 May-7 June & $3.3 \pm 0.2$ & $0.3 \pm 0.1$ & 4 & 89 & 6 & 84 \\
\hline Bloom ${ }^{a}$ & 25 & 14-21 June & $1.0 \pm 0.2$ & $3.2 \pm 0.3$ & 0 & 0 & 100 & 105 \\
\hline Postbloom ${ }^{b}$ & 24 & 28 June-5 July & $0.5 \pm 0.1$ & $2.3 \pm 0.1$ & 0 & 0 & 100 & 69 \\
\hline Prepostbloom $^{a}$ & 23 & 31 May-5 July & 0.0 & $1.4 \pm 0.2$ & 0 & 0 & 100 & 31 \\
\hline
\end{tabular}

"Five T. scripets placed in each cage.

"Three T. scrupets placed in each cage.

pleted, but before the bloom or postbloom treatment. Floret counts were not made for the prebloom-postbloom treatment to avoid disturbing sleeve cages, which were in place at the time floret counts were taken. After fruit set (15 August), the number of berries per cluster in the basal cluster was counted in all 4 treatments. Individual basal clusters were harvested on 15 October, weighed, and berries per cluster again were counted. Average berry weight was calculated for each cluster by dividing the total weight by the numbers of berries per cluster.

Paired $t$-tests ( $\alpha=0.05$ ) were used to determine whether shoot length, floret number, berry number, and berry weight at harvest differed among treatments. Separate analyses were made for each cage date.

Insecticide Trial 1996. As a follow-up to the cage experiment, a trial was set up in 1996 to determine whether an early season insecticide treatment would prevent yield loss in a commercial setting. In a mature, cane-pruned Concord vineyard, 10 replicates of 2 treatments (prebloom spray and no spray) were applied to 3-vine (1 post-length) plots. Sprayed and unsprayed treatments were applied randomly to 3-vine plots, separated by a 3-vine buffer area, in a completely randomized design. To the sprayed vines, $2.2 \mathrm{~kg}$ (AI)/ ha of carbaryl (Sevin 80S, Rhone Poulenc, Research Triangle Park, NC) was applied on 31 May. Pretreatment nymphal counts were made on the center vine of each 3-vine unit on 31 May, and posttreatment counts were made on 10 June. All T. scrupeus nymphs on each count vine were counted. On 15 June, the total number of shoots arising from retained buds in the center vine of each unit was counted.

At harvest, the total number of clusters was recorded for each of the 30 vines per treatment, and harvested fruit was weighed. Samples of 2 apical berries from 50 clusters in each 3-vine unit were weighed to determine average berry weight. Juice soluble solids (\%) were obtained from expressed juice by using a hand refractometer.

From individual vine harvest data, mean crop weight, clusters per vine, cluster weight, berry weight, and berries per cluster were calculated on a per-vine basis for each of the 10 replicates. Students $t$-tests were used to test for significant differences in yield response variables at the $\alpha=0.05$ level.

\section{Results}

Phenology and Feeding Behavior Observations. First instars were first observed on 15 May 1995 in vineyards near Lake Erie. By 22 May, they also were found in higher-elevation and cooler sites. Adult $T$. scrupeus were first observed on 12 June. The last observation of adults in vineyards occurred on 20 July.

First instars fed on shoot tips and in newly unfolding leaves. Later instars in the field were observed to feed mostly on the rachis of flower buds, but they also fed on the axil of the leaf petiole to the shoot, on both sides of immature leaves, and on the shoot tip. Nymphs presented with clusters in the laboratory were observed to insert their stylets in pedicels of individual florets, and on the rachis, with feeding bouts lasting up to $4 \mathrm{~min}$. Adults were often observed in the field resting on either side of grape leaves. They were observed to feed on shoots, leaves, and tendrils, and often on puncture wounds on the shoots caused by the grape cane gallmaker, Ampelogloglypter sesostris (LeConte). No adults were observed feeding on grape clusters. Adults also were observed feeding on midges and lepidopteran larvae, and cannibalizing other adult $T$. scrupeus. In the laboratory, adults presented with clusters made short probes into rachis tissue. Adults placed together with nymphs often fed on the nymphs, rather than on the grape cluster. In the vine caged with $T$. scrupeus adults, oval, elongate eggs ( $0.4 \mathrm{~mm}$ long) were found under the bark of grapevine trunks and cordons in late summer.

Cage Study. Developmental stages and numbers of $T$. scrupeus recovered from sleeve cages varied among cage periods (Table 1). During the prebloom period, lst to 3 rd instars developed to 4 th and 5 th instars, and most (3.3 per unit) were recovered alive. Fifth instars, caged during the bloom period were recovered as adults. Substantial mortality occurred, resulting in recovery of 1 live adult per sleeve cage and 3.2 dead adults per cage. A similar pattern was observed during the postbloom period, with 0.5 live and 2.2 dead adults recovered. No live adults were recovered from the prebloom to postbloom treatment; however, all dead individuals were adults, indicating that $T$. scrupeus nymphs were able to complete development within the sleeve cages.

Feeding by T. scrupeus nymphs during the prebloom period (Fig. 1A) significantly reduced the number of florets per cluster $(t=2.94, \mathrm{df}=20, P=0.008)$. Floret 

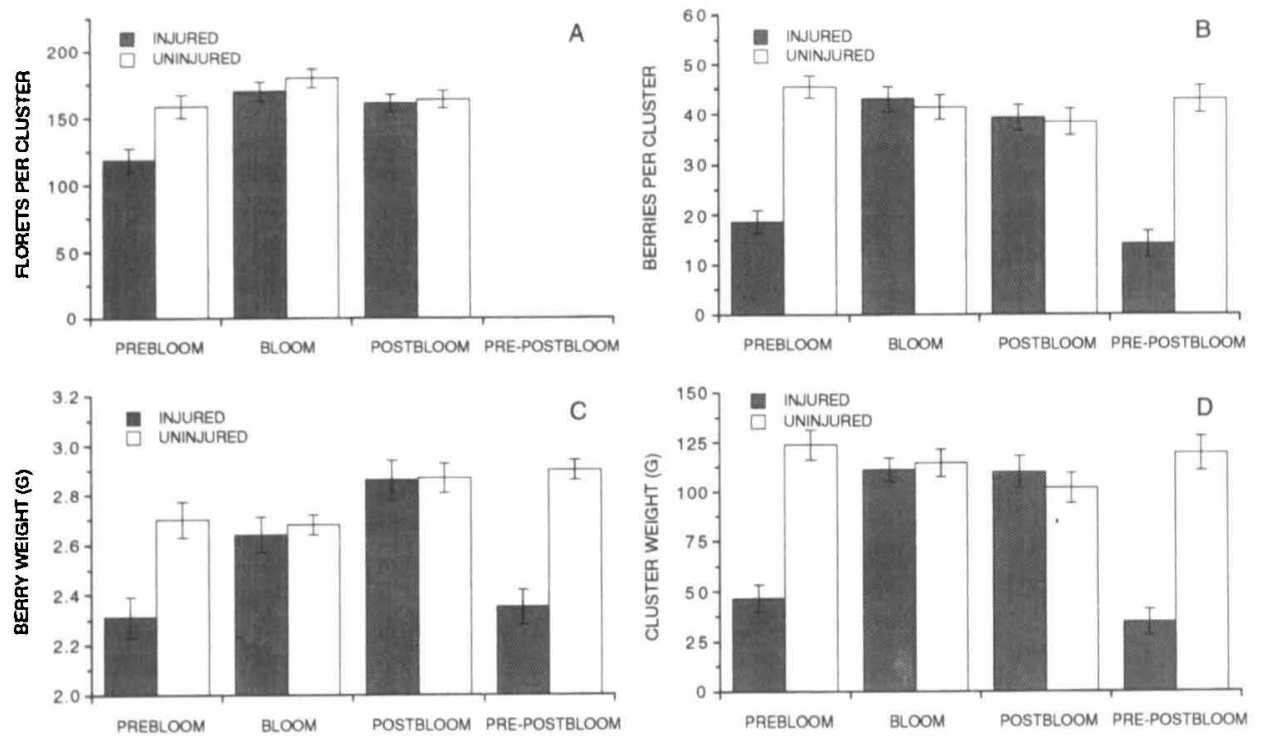

Fig. 1. Effect of feeding injury by caged $T$. scrupeus on yield components of Concord clusters. (A) florets per cluster; (B) berries per cluster; (C) berry weight; (D) cluster weight. Bars = $1 \mathrm{SEM}$.

counts were made before the bloom and postbloom periods. Prebloom and postbloom treatments did not have significantly different floret counts, which was expected because $T$. scrupeus were caged after floret counts were made (Fig, 1a). Feeding injury significantly reduced the number of berries per cluster in the prebloom $(t=7.64, \mathrm{df}=20, P<0.001)$, and prebloom to postbloom treatments $(t=6.81, \mathrm{df}=23, P<0.001)$, but not during the bloom and postbloom treatments ( $P>0.05$, Fig. 1B). T. scrupeus feeding also significantly reduced berry weight (Fig. 1C) in the prebloom ( $t=6.33, \mathrm{df}=17, P<0.001)$, and the prebloom to postbloom ( $t=6.40, \mathrm{df}=20, P<0.001$ ) treatments, but not in the bloom or postbloom treatments. As a result of these differences, per-cluster crop weight in the injured prebloom and prebloom to postbloom treatments was 38 and $29 \%$, respectively, of that observed in uninjured clusters (Fig. 1D).

1996 Vineyard Spray Trial. Total counts of $T$. scrupeus nymphs per vine revealed equal numbers per vine during the pretreatment count (Table 2). Posttreatment counts showed similar numbers in the unsprayed treatment as were present in the pretreatment counts. No T. scrupeus were observed in the sprayed treatment during posttreatment counts. No other insect pests were found in economically significant numbers in the experimental vineyard.

Shoot counts were similar for the 2 treatments, with sprayed vines having 55 shoots per vine and unsprayed having 60 shoots per vine (Table 2), indicating that vines had similar yield potential at the start of the experiment. Mean yield was significantly lower in the unsprayed treatment $(t=2.6, \mathrm{df}=18, P=0.02)$, with an average reduction of $3.6 \mathrm{~kg}$ per vine. Unsprayed vines had significantly fewer clusters per vine $(t=$ $2.91, \mathrm{df}=18, P=0.009$ ), which accounted for most of the yield reduction observed. Cluster weight in the unsprayed treatment was slightly reduced, and unsprayed clusters had slightly (but not significantly) fewer berries per cluster $(t=1.68, \mathrm{df}=18, P=0.11)$. Berry weight was not significantly affected by spray treatment. Juice soluble solids were similar for the 2 treatments.

Table 2. Effect of $T$. serupeus injury on yield components of 'Concord' grapes in a commercinl vineyard in 1996

\begin{tabular}{|c|c|c|c|c|}
\hline \multirow{2}{*}{ Attribute } & \multicolumn{2}{|c|}{ Trentment } & \multirow{2}{*}{$t^{a}$} & \multirow{2}{*}{$P$} \\
\hline & Sprayed & Unsprayed & & \\
\hline T. scrupetus/vine pretreatment & 18.5 & 19.5 & 0.20 & 0.84 \\
\hline T. scrupctus/vine posttreatment & 0 & 21.4 & 8.25 & $<0.001$ \\
\hline Bearing shoots per vine & 55.1 & 60.3 & 0.83 & 0.41 \\
\hline Yield (kg/vine) & 14.1 & 10.4 & 2.61 & 0.018 \\
\hline Clusters/vine & 165.4 & 131.8 & 2.91 & 0.009 \\
\hline Cluster wt, g & 84.6 & 78.8 & 1.07 & 0.30 \\
\hline Berries per cluster & 30.5 & 27.3 & 1.68 & 0.11 \\
\hline Berry wt, g & 2.8 & 2.9 & 1.17 & 0.26 \\
\hline Juice soluble solids, \% & 13.6 & 14.2 & 0.86 & 0.40 \\
\hline
\end{tabular}

$a_{n}=10$ per treatment, $\mathrm{df}=18$. 


\section{Discussion}

Our observations of phenology, although incomplete, suggest that $T$. scrupeus completes 1 generation per year on grapes. It is unclear whether additional generations are completed on other hosts, although Felt (1915) cites several alternate host plants. We hypothesize that $T$. scrupeus overwinters in the egg stage on dormant canes and trunks, although we have not verified that the eggs we found on vines caged with adults were those of T. scrupeus. Nonetheless, the early appearance of nymphs shortly after bud break, and the absence of adults at this time of the season, support this hypothesis.

Results of the cage experiments demonstrated that feeding by early instars from 31 May through 6 June had a significant effect on cluster development, reducing the number of florets by $25 \%$, average berry number by $59 \%$, and average berry weight by $14 \%$. The cumulative effect of the injury reduced total crop weight (on a per-cluster basis) by $68 \%$. In contrast feeding during the bloom (14-21 June) and postbloom (28 June-5 July) period did not have any affect on cluster size or berry weight. Feeding by caged $T$. scrupeus throughout the prebloom to postbloom period (31 May-5 July), affected cluster development in a similar manner and extent as prebloom feeding, with average berry number reduced by $68 \%$ and berry weight reduced by $19 \%$, resulting in a $71 \%$ reduction in average cluster weight. Similarity of the results from the prebloom and prebloom-postbloom periods suggests that feeding during the 3 -wk period from appearance of lst instars (15-22 May; $12-24 \mathrm{~cm}$ shoot length) to about the 2nd wk in June $(40-\mathrm{cm}$ shoot length) is crucial to producing injury. This corresponds to a period of rapid shoot elongation and cluster formation in grapes, with average shoot length during the prebloom period ranging from 24 to $40 \mathrm{~cm}$.

The 1996, commercial vineyard spray trial confirmed results observed in the field cage experiment, and demonstrated that even relatively low-density $T$. scrupeus populations can produce significant economic injury, as was suggested by Felt (1915). Twenty nymphs per vine resulted in a mean reduction of 3.6 kg per vine ( $26 \%$ reduction in crop weight), suggesting that each nymph was responsible for $0.18 \mathrm{~kg}$ of crop loss per vine, or $240 \mathrm{~kg}$ of crop loss per hectare. This level of crop loss suggests that treatment would be economically justified at population densities as low as 1 nymph per vine. In contrast to the 1995 cage study, where feeding reduced average cluster size and berry weight, most of the loss in the 1996 study was associated with fewer harvested clusters per vine. Injured vines had 33 fewer clusters per vine, and yield was reduced by the equivalent of 43 clusters per vine. This suggests that feeding injury by $T$. scrupeus in this trial resulted in abortion of entire clusters, rather than the partial cluster injury observed in the 1995 cage study.

Feeding injury resulted in both loss of florets and injury to the rachis during the prebloom period. This type of feeding injury is similar to that caused by other mirids. Feeding by tamished plant bug, Lygus line- olaris (Palisot de Beauvois), is associated with plant stunting, malformation of leaves, and flower abscission in alfalfa (Jensen et al. 1991), grain amaranth (Olsen and Wilson 1990), and cotton (Snodgrass et al. 1984). On apple, feeding by the mirids Atractatomus mali (Meyer) and Campylomma verbasci (Meyer) shortly after bloom results in abortion of the fruit or cosmetic deformities (Bishop 1993a, b), whereas late instars and adults of both species are predatory (Arnoldi et al. 1992, Novak and Achtziger 1995). Our observations of feeding behavior of nymphs and adults suggest that $T$. scrupeus nymphs are phytophagous, and adults also are predatory on other arthropods. This change in diet by adults may explain both the lack of cluster injury observed in the 1995 cage study in the bloom and postbloom treatments, and also why an average of 0.5-1 adults (Table 1) was recovered alive from the sleeve cages. Recovering one or less live adult per cage would be consistent with cannibalism of the other caged individuals.

The 1995 cage experiment demonstrated that cluster injury was associated exclusively with nymphal feeding during the prebloom period. The 1996 field spray experiment demonstrated that a prebloom application of carbaryl to prevent nymphal feeding can protect vines from significant yield loss from as little as 1 nymph per vine.

Although these experiments have demonstrated that $T$. scrupeus is an important pest warranting treatment, little is known about its distribution within vineyards or the relative frequency of infestations in commercial vineyards. Our observations indicate that it is probably a sporadic pest, and that infestations are concentrated near the edge of vineyards bordering woodlots. Further research is needed to verify these observations and to develop monitoring and decisionmaking guidelines for managing this pest.

\section{Acknowledgments}

We thank R. Dunst and C. Cummings (Vineyard Research Laboratory, Cornell University, Fredonia, NY) for technical assistance. This work was funded by the New York Wine and Grape Foundation, Lake Erie Regional Grape Research Program, and the Grape Production Research Fund.

\section{References Cited}

Arnoldi, D., R. K. Stewart, and G. Boivin. 1992. Predatory mirids of the green apple aphid Aphis pomi, Tetranychus urticae, and the european red mite Panonychus ulmi in apple orchards in Quebec. Entomophaga 37: 283-292.

Bishop, S. 1993a. Apple brown bug. Nova Scotia orchard pest management fact sheets. Series 4: 3. Nova Scotia Tree Fruit Research Foundation, Halifax.

Bishop, S. 1993b. Mullein bug. Nova Scotia orchard pest management fact sheets. Series 4: 4 . Nova Scotia Tree Fruit Research Foundation, Halifax.

Felt, E. P. 1915. Banded grape bug, Paracalocoris scrupetus Say, pp. 41-44, Twenty-ninth report of the state entomologist on injurious and other insects of the state of New York 1916. N.Y. State Mus. Bull. 175.

Jensen, B. M., J. L. Wedberg, and D. B. Hogg. 1991. Assessment of damage caused by tarnished plant bug and alfalfa 
plant bug (Hemiptera: Miridae) on alfalfa grown for forage in Wisconsin. J. Econ. Entomol. 84: 1024-1027.

Jubb, G. R. 1979. Little known grape insect pests. Am. Wine Soc. J. 11: $46-47$.

Novak, H. , and R. Achtziger. 1995. Influence of heteropteran predators (Heteroptera: Anthocoridae, Miridae) on larval populations of hawthorn psyllids (Homoptera: Psyllidae). J. Appl. Entomol. 119: 479-486.

Olson, D. L., and R. L. Wilson. 1990. Tarnished plant bug (Hemiptera: Miridae): effect on seed weight of grain amaranth. J. Econ. Entomol, 83: 2443-2447.
Snodgrass, G. L., W. P. Scott, and J. W. Smith. 1984. Host plants and seasonal distribution of the tarnished plant bug (Hemiptera: Miridae) in the delta of Arkansas, Louisiana, and Mississippi. Environ. Entomol. 13: 110-116.

Received for publication 12 February 1997; accepted 14 October 1997. 